\title{
A single nucleotide polymorphism of the TNRC9 gene associated with breast cancer risk in Chinese Han women
}

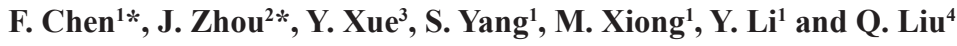 \\ ${ }^{1}$ Life Sciences School of Hubei University, Wuchang, Wuhan, China \\ ${ }^{2}$ Wuhan Tuberculosis Dispensary, Qiaokou, Wuhan, China \\ ${ }^{3}$ Laboratory of Medical Engineering, \\ College of Medical Technology and Engineering, \\ Henan University of Science and Technology, Luoyang, China \\ ${ }^{4}$ Pharmacy School of Hainan Medical College, Haikou, China \\ *These authors contributed equally to this study. \\ Corresponding author: Q. Liu \\ E-mail: haiyiqueen@163.com
}

Genet. Mol. Res. 13 (1): 182-187 (2014)

Received March 27, 2013

Accepted November 30, 2013

Published January 10, 2014

DOI http://dx.doi.org/10.4238/2014.January.10.9

\begin{abstract}
A single nucleotide polymorphism (SNP) in the TNRC9 gene was identified as a breast cancer susceptibility genetic variant in recent genome-wide association studies of women of European ancestry. We investigated whether TNRC9 polymorphisms are associated with risk of breast cancer in Chinese women of the Han nationality. We genotyped the SNPs rs 3803662 , rs 1362548 , rs 1123428 in 870 women, including 388 breast cancer patients and 482 healthy controls, via the PCR-single strand conformation polymorphism procedure and by sequence detection. We found that the T allele and the TT genotype of the SNP rs38033662 is significantly associated with risk for breast cancer in Chinese Han women; however, no significant association was found for rs 1362548 or rs 1123428 . We
\end{abstract}


conclude that SNP rs3803662 is a putative risk factor for breast cancer in Chinese Han women.

Key words: Trinucleotide-repeat-containing 9; Breast cancer; SNP; Han nationality: PCR-SSCP

\section{INTRODUCTION}

Breast cancer is a multifactorial disease. Environment, genetics, and immunological defects are major factors in the etiology of breast cancer (Parkin et al., 2005). It has been reported that close relatives of patients have an approximately 2 -fold increased risk of cancer, and the genetic factors believed to be most crucial have been revealed from twin studies (Peto and Mack, 2000; Pharoah et al., 2004).

TNRC9 (trinucleotide-repeat-containing 9), also termed TOX3, was first identified in a screen for transcripts containing trinucleotide (CAG) repeat expansions (Margolis et al., 1997). It is a gene located at chromosome 16q12, and has been identified as a risk factor for breast cancer through genome-wide association studies (GWAS) (Stacey et al., 2007). There is little further data on TNRC9, but it is known that a single nucleotide polymorphism (SNP) near its 5 '-end appears to be strongly associated with breast cancer susceptibility (Easton et al., 2007; Huijts et al., 2007). Several polymorphisms have been identified in the TNRC9 gene: rs3803662, rs 12443621, and rs 8051542 (Huijts et al., 2007). GWAS indicated that TNRC9 rs3803662 exhibited a stronger association with breast cancer (Easton et al., 2007; Stacey et al., 2007; Thomas et al., 2009). SNP rs3803662 lies $8 \mathrm{~kb}$ upstream of TNRC9 and has been observed to be associated with an increased risk of breast cancer in both BRCA1 and BRCA2 mutation carriers (Antoniou et al., 2008). The rs3803662 polymorphism is either restricted to or more strongly associated with estrogen receptor (ER)-positive tumors than those ERnegative cancers (Stacey et al., 2007; Garcia-Closas et al., 2008; Dittmer et al., 2011). Several epidemiological studies have evaluated the association between TNRC9 polymorphisms and breast cancer risk, but the results remain inconclusive according to different ethnic groups (Zheng et al., 2009; Li et al., 2009; Ruiz-Narváez et al., 2010). In the present study, we investigated the rs 3803662 , rs 1362548 and rs 1123428 polymorphisms of TNRC9 associated with risk of breast cancer in Chinese Han women.

\section{MATERIAL AND METHODS}

\section{Study population}

Groups of 388 Chinese women of the Han nationality with breast cancer (patient group) and 482 healthy women of the same ethnic group (control group) were used in this study. All patients were diagnosed with a primary breast tumor in the Cancer Hospital of Hubei Province from May 2011 to June 2012. Clinical characteristics were recorded by tracing case-histories and interviews with all patients. ER and progesterone receptor (PR) status of breast cancers was established with an immunohistochemical (Liang et al., 2010), where the reaction was considered to be positive when the percentage of stained cells was equal to or greater than $10 \%$. The demographic characteristics of patients and healthy controls are shown 
in Table 1. The study was approved by the Ethics Committee of the Life Science School of Hubei University. All subjects gave their written informed consent.

\section{DNA extraction and genotyping}

Genomic DNA was isolated from peripheral blood by the conventional proteinase K digestion/phenol-chloroform extraction method. TNRC9 SNPs (rs3803662, rs1362548 and rs1123428) were genotyped by PCR-SSCP and DNA sequencing. The assays were performed in a $5-\mu \mathrm{L}$ reaction mixture containing $1 \mathrm{X}$ TaqMan PCR core reagents, $5 \mathrm{mM} \mathrm{MgCl}, 200 \mathrm{nM}$ of each PCR primer, $100 \mathrm{nM}$ MGB probes, $0.5 \mathrm{U}$ AmpliTaq Gold, $0.2 \mathrm{U}$ AmpErase UNG, and 5 ng genomic DNA. Approximately $1 \%$ of duplicated samples were used as internal controls. Discrepancies were not observed.

\section{Statistical analysis}

All data were analyzed with the SPSS13.0 statistical software (SPSS, Inc., Chicago, IL, USA). Differences between cases and controls based on demographic characteristics were calculated by $\chi^{2}$ tests (for categorical variables) or the Student $t$-test (for continuous variables). Hardy-Weinberg equilibrium was assessed using a $\chi^{2}$ test in each group. The allelic and genotypic frequencies were determined by direct counting, and statistical comparison was performed by the $\chi^{2}$ test with Yates correction or the Fisher exact test. Odds ratios (OR) and 95\% confidence intervals (CI) were calculated for the disease in carriers of specific alleles. When $\mathrm{P}$ was less than 0.05 , the difference was considered to be statistically significant.

\section{RESULTS}

The characteristics of healthy controls and breast cancer patients are shown in Table 1. The age range for the two groups matched quite well $(P>0.6)$. The age of first live birth, menopausal status, and number of pregnancies showed no significant difference between patient and control groups. The occurrence of breast cancer in first-degree relatives was markedly higher than in the control group ( $26.55 v s$ 19.29\%, $\mathrm{P}=0.011)$. The percentage of breast cancer patients who never breastfed was higher than for the controls, but not statistically significant (39.68 vs 33.76\%, $\mathrm{P}=0.07)$. ER and $\mathrm{PR}$ data showed a positive rate higher than a negative rate (55.93 vs $44.07 \%$ and 57.47 vs $42.53 \%$, respectively).

Allelic frequencies of TNRC9 rs3803662, rs1362548 and rs1123428 between breast cancer patients and controls are summarized in Table 2. The frequency of the T allele of SNP rs3803662 in breast cancer patients was markedly higher than in controls (36vs 31\%, P = $0.041, \mathrm{OR}=1.23,95 \% \mathrm{CI}=1.01-1.50)$. Allelic frequencies for the other two SNPs showed no statistical difference $(\mathrm{P}>0.05)$.

Genotype frequencies of polymorphic variants of TNRC9 for patient and control groups are summarized in Table 3. Frequencies of the TT genotype for SNP rs3803662 was significantly different between the patient and control groups $(\mathrm{P}=0.013)$. The TT genotype frequency of rs3803662 in patients was greater than controls $(13 v s 8 \%$, OR $=1.83,95 \% \mathrm{CI}=1.15-2.92)$, suggesting that the TT genotype at rs 3803662 is a breast cancer risk factor. For other genotypes, rs1362548 and rs1123428, patients and controls showed no significant difference $(\mathrm{P}>0.05)$. 
Table 1. Characteristics of healthy controls and breast cancer patients.

\begin{tabular}{|c|c|c|c|}
\hline Variables & Patients $(\mathrm{N}=388)$ & Controls $(\mathrm{N}=482)$ & $\mathrm{P}$ value \\
\hline Age [years range (mean $\pm \mathrm{SD})]$ & $36-68(52.23 \pm 12.61)$ & $22-65(51.75 \pm 11.87)$ & $0.623^{\mathrm{c}}$ \\
\hline Age at first live birth $\left[\right.$ year $(\text { mean } \pm \text { SD) }]^{\mathrm{a}}$ & $25.62 \pm 3.25$ & $23.67 \pm 3.43$ & $0.342^{\mathrm{c}}$ \\
\hline \multicolumn{4}{|l|}{ Menopausal status } \\
\hline Premenopausal & $184(47.42 \%)$ & $223(46.27 \%)$ & \multirow[t]{2}{*}{$0.734^{\mathrm{d}}$} \\
\hline Post-menopausal & $204(52.58 \%)$ & $259(53.73 \%)$ & \\
\hline \multicolumn{4}{|l|}{ Family history of cancer } \\
\hline Positive & $103(26.55 \%)$ & $93(19.29 \%)$ & \multirow[t]{2}{*}{$0.011^{\mathrm{d}}$} \\
\hline Negative & $285(73.45 \%)$ & $389(80.71 \%)$ & \\
\hline \multicolumn{4}{|l|}{ Pregnancy ${ }^{\mathrm{b}}$} \\
\hline 1 & $69(17.78 \%)$ & $97(20.12 \%)$ & \multirow[t]{4}{*}{$0.208^{\mathrm{d}}$} \\
\hline 2 & $110(28.35 \%)$ & $150(31.75 \%)$ & \\
\hline 3 & $98(25.26 \%)$ & $93(19.29 \%)$ & \\
\hline$\geq 4$ & $101(28.61 \%)$ & $131(28.84 \%)$ & \\
\hline \multicolumn{4}{|l|}{ Breastfeeding ${ }^{\mathrm{b}}$} \\
\hline Ever & $228(60.32 \%)$ & $312(66.24 \%)$ & \multirow[t]{2}{*}{$0.075^{\mathrm{d}}$} \\
\hline Never & $150(39.68 \%)$ & $159(33.76 \%)$ & \\
\hline \multicolumn{4}{|l|}{ ER } \\
\hline Positive & $217(55.93 \%)$ & & \\
\hline Negative & $171(44.07 \%)$ & & \\
\hline \multicolumn{4}{|l|}{ PR } \\
\hline Positive & $223(57.47 \%)$ & & \\
\hline Negative & $165(42.53 \%)$ & & \\
\hline
\end{tabular}

${ }^{a}$ Age at first live birth information for 70 breast cancer cases $(95.36 \%)$ and 459 controls $(95.23 \%)$. ${ }^{\text {bregnancy }}$ and breastfeeding were available in 378 breast cancer cases $(97.42 \%)$ and 471 controls $(97.72 \%)$. ER = estrogen receptor; $\mathrm{PR}=$ progesterone receptor. ${ }^{\mathrm{c}} \mathrm{P}$ value between patients and controls, for the $t$-test. ${ }^{\mathrm{d}} \mathrm{P}$ value between patients and controls, for the $\chi^{2}$ test.

\begin{tabular}{|c|c|c|c|c|c|c|}
\hline \multirow[t]{2}{*}{ SNP ID } & \multirow[t]{2}{*}{ Allele } & \multicolumn{2}{|c|}{ Allelic frequency } & \multicolumn{2}{|c|}{ Statistic } & \multirow[t]{2}{*}{ OR $(95 \% \mathrm{CI})$} \\
\hline & & Patients [N (Freq.)] & Controls [N (Freq.)] & $\chi^{2}$ & P value & \\
\hline $\begin{array}{l}\text { rs3803662 } \\
\text { HWE (P) }\end{array}$ & $\mathrm{T}$ & $280(0.36)$ & $\begin{array}{c}303(0.31) \\
0.10\end{array}$ & 4.174 & $0.041^{*}$ & $1.23(1.01-1.50)$ \\
\hline $\begin{array}{l}\text { rs1362548 } \\
\text { HWE (P) }\end{array}$ & G & $427(0.55)$ & $\begin{array}{c}550(0.57) \\
0.14\end{array}$ & 0.718 & 0.397 & $0.92(0.76-1.11)$ \\
\hline $\begin{array}{l}\text { rs1123428 } \\
\text { HWE (P) }\end{array}$ & $\mathrm{T}$ & $343(0.44)$ & $\begin{array}{c}447(0.46) \\
0.17\end{array}$ & 0.815 & 0.367 & $0.92(0.76-1.11)$ \\
\hline
\end{tabular}

$\mathrm{SNP}=$ single nucleotide polymorphism; HWE $=$ Hardy-Weinberg equilibrium; OR $=$ odds ratios; $95 \% \mathrm{CI}=95 \%$ confidence intervals; $\mathrm{N}=$ number of alleles; Freq. $=$ frequency. ${ }^{*} \mathrm{P}<0.05$.

Table 3. Genotype frequencies of polymorphic variants of the TNRC9 gene in patients with breast cancer and healthy controls.

\begin{tabular}{|c|c|c|c|c|c|}
\hline SNP sites & Genotype & Patients [N (Freq.)] & Controls [N (Freq.)] & $P$ value & OR $(95 \% \mathrm{CI})$ \\
\hline \multirow[t]{3}{*}{ rs 3803662} & $\mathrm{CT}$ & $159(0.41)$ & $217(0.45)$ & & 1 \\
\hline & $\mathrm{CT}$ & $178(0.46)$ & $227(0.47)$ & 0.639 & $1.07(0.81-1.42)$ \\
\hline & $\mathrm{TT}$ & $51(0.13)$ & $38(0.08)$ & $0.013 *$ & $1.83(1.15-2.92)$ \\
\hline \multirow[t]{3}{*}{ rs 1362548} & $\mathrm{CC}$ & $77(0.30)$ & $81(0.41)$ & & \\
\hline & CG & $195(0.40)$ & $252(0.46)$ & 0.27 & $0.81(0.57-1.17)$ \\
\hline & GG & $116(0.30)$ & $149(0.31)$ & 0.32 & $0.82(0.55-1.22)$ \\
\hline \multirow[t]{3}{*}{ rs 1123428} & AA & $130(0.34)$ & $155(0.32)$ & & \\
\hline & AT & $173(0.45)$ & $207(0.43)$ & 0.98 & $0.99(0.73-1.36)$ \\
\hline & $\mathrm{TT}$ & $85(0.22)$ & $120(0.25)$ & 0.36 & $0.85(0.59-1.21)$ \\
\hline
\end{tabular}

$\mathrm{SNP}=$ single nucleotide polymorphism; $\mathrm{OR}=$ odds ratios; $95 \% \mathrm{CI}=95 \%$ confidence intervals; $\mathrm{N}=$ number of alleles; Freq. $=$ frequency. $* \mathrm{P}<0.05$. 


\section{DISCUSSION}

Our results demonstrating that the T allele and TT genotype of SNP rs3803662 are a risk factor is consistent with the GWAS mentioned above (Thomas et al., 2009; Zheng et al., 2009). Several epidemiological studies have evaluated the association between TNRC9 polymorphisms and breast cancer risk in Chinese women (Li et al., 2009; Liang et al., 2010); however, the results remain inconclusive, partially because of the possible negligible effect of polymorphism on breast cancer risk in different nationalities of China and the relatively small sample size used in the previously published studies. Our investigation showed that rs3803662 was associated with breast cancer risk in Chinese Han women, while rs1362548 and rs1123428 were unrelated. Whether rs3803662 has linkage disequilibrium with other SNPs in TNRC9 and haplotype associated with breast cancer requires further inquiry.

Little is known about the mechanism of TNRC9 in breast cancer, but some reports suggest its potential to play the role of a transcription factor and it has been implicated in breast cancer metastasis of the bone (Smid et al., 2006). The SNP appears to be strongly associated with breast cancer susceptibility (Huijts et al., 2007; Stacey et al., 2007). Several reports have demonstrated that genetic variants in TNRC9 are associated with risk of ERpositive breast cancer (Liang et al., 2010; Dittmer et al., 2011). In our study, both ER- and PR-positive patients were more susceptible to breast cancer than ER- or PR-negative patients (Table 1). The data supported the hypothesis that TNRC9 contributes to breast cancer occurrence through pathways related to estrogen and/or progesterone.

In conclusion, our results suggest that the T allele and the TT genotype of TNRC9 rs3803662 are significantly correlated with breast cancer risk and that no significant association exists with TNRC9 rs1362548 and rs1123428. Moreover, it is necessary to conduct larger sample studies considering gene-gene and gene-environment interactions.

\section{ACKNOWLEDGMENTS}

Research supported by the National Natural Science Foundation of China (\#30801014 and \#31001051), the Department of Education of Hubei Province (\#Q20091001) and the Wuhan Health Bureau (\#WH12A03).

\section{Conflicts of interest}

The authors declare no conflict of interest.

\section{REFERENCES}

Antoniou AC, Spurdle AB, Sinilnikova OM, Healey S, et al. (2008). Common breast cancer-predisposition alleles are associated with breast cancer risk in BRCA1 and BRCA2 mutation carriers. Am. J. Hum. Genet. 82: 937-948.

Dittmer S, Kovacs Z, Yuan SH, Siszler G, et al. (2011). TOX3 is a neuronal survival factor that induces transcription depending on the presence of CITED1 or phosphorylated CREB in the transcriptionally active complex. J. Cell Sci. 124: 252-260.

Easton DF, Pooley KA, Dunning AM, Pharoah PD, et al. (2007). Genome-wide association study identifies novel breast cancer susceptibility loci. Nature 447: 1087-1093.

Garcia-Closas M, Hall P, Nevanlinna H, Pooley K, et al. (2008). Heterogeneity of breast cancer associations with five susceptibility loci by clinical and pathological characteristics. PLoS Genet. 4: e1000054. 
Huijts PE, Vreeswijk MP, Kroeze-Jansema KH, Jacobi CE, et al. (2007). Clinical correlates of low-risk variants in FGFR2, TNRC9, MAP3K1, LSP1 and 8q24 in a Dutch cohort of incident breast cancer cases. Breast Cancer Res. 9: R78.

Li L, Zhou X, Huang Z, Liu Z, et al. (2009). TNRC9/LOC643714 polymorphisms are not associated with breast cancer risk in Chinese women. Eur. J. Cancer Prev. 18: 285-290.

Liang J, Chen P, Hu Z, Shen H, et al. (2010). Genetic variants in trinucleotide repeat-containing 9 (TNRC9) are associated with risk of estrogen receptor positive breast cancer in a Chinese population. Breast Cancer Res. Treat. 124: 237-241.

Margolis RL, Abraham MR, Gatchell SB, Li SH, et al. (1997). cDNAs with long CAG trinucleotide repeats from human brain. Hum. Genet. 100: 114-122.

Parkin DM, Bray F, Ferlay J and Pisani P (2005). Global cancer statistics, 2002. CA Cancer J. Clin. 55: 74-108.

Peto J and Mack TM (2000). High constant incidence in twins and other relatives of women with breast cancer. Nat. Genet. 26: 411-414.

Pharoah PD, Dunning AM, Ponder BA and Easton DF (2004). Association studies for finding cancer-susceptibility genetic variants. Nat. Rev. Cancer 4: 850-860.

Ruiz-Narváez EA, Rosenberg L, Cozier YC, Cupples LA, et al. (2010). Polymorphisms in the TOX3/LOC643714 locus and risk of breast cancer in African-American women. Cancer Epidemiol. Biomarkers Prev. 19: 1320-1327.

Smid M, Wang Y, Klijn JG, Sieuwerts AM, et al. (2006). Genes associated with breast cancer metastatic to bone. J. Clin. Oncol. 24: 2261-2267.

Stacey SN, Manolescu A, Sulem P, Rafnar T, et al. (2007). Common variants on chromosomes 2q35 and 16q12 confer susceptibility to estrogen receptor-positive breast cancer. Nat. Genet. 39: 865-869.

Thomas G, Jacobs KB, Kraft P, Yeager M, et al. (2009). A multistage genome-wide association study in breast cancer identifies two new risk alleles at 1p11.2 and 14q24.1 (RAD51L1). Nat. Genet. 41: 579-584.

Zheng W, Long J, Gao YT, Li C, et al. (2009). Genome-wide association study identifies a new breast cancer susceptibility locus at 6q25.1. Nat. Genet. 41: 324-328. 